THURSDAY, MAY 3I, 1877

\section{THE UNIVERSITIES BILL AND UNIVERSITY} MOVEMENTS

THE monotonous progress of the Oxford and Cambridge Bill through the House of Commons has never been interrupted. The Government having drawn its measure, consents to modify it in a few trivial points, but wherever it does not consent, the House accepts it and passes it as an elementary matter of party discipline. Very few of the amendments are of serious importance. Lord Edmond Fitzmaurice has added perhaps the most valuable. He enables the Universities to give a definite status and payment for any special educational work done out of the University under its control. Thus the funds of Oxford and Cambridge may be freely used in support of their missionary efforts in the large and neglected towns of England. There is no reason why permanent educational centres should not be established under this clause in any part of England. Any College with too much money can assign a sufficient portion of it to the advancement of learning in the neglected provinces. Leeds, Bristol, Birmingham, Halifax, Sheffield have had university men lecturing in their midst under the University Extension Scheme, and Lord Edmond Fitzmaur ice's amendment invites the colleges to support and endow this movement. Under it the "idle fellows" who now run off to the bar will be drawn more and more into teaching, for teaching will open to them more and more of a career. No doubt there is risk that the possibility of such grants may paralyse local effort. But as yet it is only a possibility, and the colleges may be trusted to distribute their money only in places where adequate local effort cannot be expected. Another amendment by Mr. Trevelyan enables the Commissioners to review the conditions under which university emoluments can be given, especially those relating to age. There is no doubt that the age of undergraduates has increased, is increasing, and ought to be diminished. The honour man keeps back at his school as long as possible in order to make sure of getting his entrance scholarship. Even if the age at which entrance scholarships can be taken were restricted, honour men might in many cases delay so as to have a better chance after they come up of the scholarships and fellowships which are to be gained while in residence. It is reasonable to say that the work which a man is to do under the pressure of a prize examination ought to be over by twenty-one. What comes after is another matter. The competitions of the University imply a discipline which is admirable for youth "under tutors and governors," but which is merely fatiguing to men of mature intellect with serious objects in life.

A clause is to be brought up by Mr. Goschen on the report which provides that the Commissioners shall first publish the main outlines of their plans before they are allowed to apply them in detail. Certainly it seems odd that Parliament should consent to throw the whole of the questions affecting the Universities into the hands of any body of Commissioners without asking for some statement from them by which they may discover the general drift of their ideas and the character they propose to give their work. It is of great importance that before any one of them is dealt with the Colleges should know on what principles it is proposed to deal with all of them, and what are the objects to which, in the opinion of the Commissioners, the money taken should be applied. In an amusing letter to the Pall Mall Gazette a few days ago, $\mathrm{Mr}$. Dodgson, of Christchurch, represents science at Oxford as first modestly asking endowment to enable her to teach, next claiming endowment for boys to be sent to her to be taught, and lastly demanding an endowment to enable her to "think." It is an amusing travestie of the claims of the more advanced and extreme "researchers," and it is natural to ask what is the view of the Commissioners on the subject.

Since Parliament separated for the Whitsuntide holidays two things have happened in Oxford, which indicate the drift of that University opinion which in the end controls the actions even of Commissioners. The first was the Oxford scheme for new professorships. It was an echo - certainly an exaggerated one-of a similar scheme proposed some time ago by some similar board of studies in Cambridge, and they both showed that the leading members of the two Universities are not indisposed to consider very large and radical schemes of reform. Both of them will give fresh strength to the party, more powerful perhaps in sympathy than in numbers, which is suspicious not merely of proposed researchers with nothing to do but " to think," but of possible professors with very few lectures to deliver, and still fewer students to hear them. It is the commonest and the most vulgar argument against such proposals that they are really drawn in the pecuniary interest of the class of actual and possible professors who are numerous in the Universities. The Hebdomadal Board shows us at any rate one distinct way in which it is possible to utilize the endowments of Oxford and Cambridge, and they put fairly before us the question whether it is not a better way than the prize fellowship system.

The second event of the past week was the discussion in congregation of the new resolutions on natural science degrees. It is proposed that instead of there being one kind of degree and only one-that in Arts--open to ordinary undergraduates, a new degree shall be created in Natural Science. The Bachelor of Arts has to pass three examinations, at which he has to show proficiency in Latin and Greek. It is proposed that the new Bachelor of Science should be let off with Latin or Greek, the missing classical language being replaced by German or French. The Bachelor of Science was meant to know more mathematics than the Bachelor of Arts, but the mathematical men have pressed the question whether mathematics itself is not a science, and whether mathematical honour men ought not to be let off as well as experimental men with one dead language. So far as things have yet shown, Oxford is in favour of the change, and eager to consider the case of the mathematicians. These are, in fact, the proposals of the Duke of Devonshire's Commission. We desire to speak with the greatest possible respect of those who maintain the status quo of the two classical languages, but it seems to us impossible to ignore the fact that the Greek learned by the pass man is about as much of a "possession for ever" as the Hebrew of most clergymen. It is begun late ; it is not carried far enough to give the student any real pleasure in reading a Greek book for 
himself; it is thrown aside as soon as its use, which is solely a "pass" use, is over, and done with. Mr. Sidgwick says, with perfect fairness, that "the study of Greek is one thing, the knowledge of the Alcestis and the study of Mr. Bohn's translation of it another." That the University should have voted in this sense by sixty-three votes to forty, and expressed its desire to treat the mathematicians as entitled to a similar relief by twenty-seven to fourteen is a conclusive proof that the world moves even at Oxford. Many of those who are best acquainted with that University indeed declare that it is there only that it does move-mat all events, that it is only there that it moves by "leaps and bounds," as British commerce used to do in the happy days of Mr. Gladstone's ministry! Certainly the votes of Oxford are often more liberal than those of London, and we cannot doubt that whenever the new Commission sets to work it will find as much impulse as obstruction from that great University. Of Cambridge itself it has ceased to be true to say that she maintains her usual attitude of magnificent repose. The universities are anxious to reform themselves if they only know how-the Commissioners will be happy to assist them if they only get power enough-and we may perhaps hope that a few "thinkers" may get something out of the reconstruction better than the very plain living with which their "high thinking" has hitherto been so commonly coupled.

\section{THE NEED OF MUSEUM REFORM}

$\mathrm{F}_{\mathrm{EW}}$ of the many subjects now pressing themselves on the attention of the public are more important than that of museums, of the work which they are doing now in general education, and what they may reasonably be expected to do in the future. It is one which has occupied my mind for many years, and on which I venture to offer the following remarks.

The collecting instinct, the desire to accumulate what strikes the fancy, is so universal in all minds lifted above the satisfaction of the mere animal needs, that its absence is to be viewed as an infirmity or misfortune analogous to colour blindness or deafness. It is present in some form or another in most savages, and even in some birds, such as the bower-bird. It is based ultimately on the principle of curiosity combined with that of selfishness. Poor and much to be pitied is the man who has it not. The collections which result from it bear the stamp of the individual who makes them, and are as various as his tastes. They may be conveniently termed museum units, which, like molecules, have a tendency to coalesce into bodies of greater orless size, and thus constitute museums. These are of high or low organisation according as the units keep or lose the stamp of the individual, and have been moulded into one living whole or are dissociated. They are highly organised and valuable if the parts are duly subordinated to each other and brought into a living relationship ; they are lowly organised and comparatively worthless if they remain as mere assemblages of units placed side by side without organic connection and without a common life.

Unfortunately in this country the provincial museums mostly belong to this latter class. It is that which takes shelter for the most part in the top rooms of Mechanics Institutes and in the holes and corners of Free Libraries and Museums. In one instance which occurs to me, you see a huge plaster cast of a heathen divinity surrounded by fossils, stuffed crocouiles, minerals, and models of various articles such as Chinese junks. In another, a museum unit takes the form of a glass case containing a fragment of human skull and a piece of oatcake labelled " fragment of human skull very much like a piece of oatcake." In a third, wax models are exhibited of a pound weight of veal, pork, and mutton chops, cod fish, turnips, potatees, carrots, and parsnips, which must have cost the value of the originals many times over, with labels explaining their chemical constitution, and how much flesh and fat they will make-just as if the public were macquainted with those articles of food, and required any information as to what these names really cover. Strangely enough this museum unit appears modern. In very many museuns art is not separated from natural history, nor from etbnology, and the eye of the beholder takes in at a glance the picture of a local worthy, a big fossil, a few cups and saucers, a piece of cloth from the South Seas, a war club or two, anci very possibly a mummy. The result of such an association as this, of articles which have no sort of relationship with the rest, is to convert the whole into rubbish, using 'the word in the Palmerstonian sense of being "matter in the wrong place." I do not mean to say that museums of this low order are useless. In default of better they are useful, just in proportion as they encourage the collecting instinct in the beholders. They may ultimately arrive at the higher stage of development. It is, however, a reproach to this country that museums of this low type should be found at this time, not merely in the smaller towns, but in some of the more important centres of population. They constitute a serious blot on our educational system, which we are striving to make as perfect as possible, since they are worse than 11seless for purposes of teaching. Instead of the natural harmony of things, they put before the mind a fortuitous concourse of atoms which is a very chaos.

While this state of things prevails largely in this country, there is no room for astonishment that museums of natural history hold the position which they do hold in the public mind. They, are looked upon' as haunts of the mere specialist, and as altogether outside any scheme for the advancement of the higher studies. If they are sufficiently attractive to be visited, they are treated as places of amusement, in which "a happy day" may be spent, instead of places of instruction. They are sometimes avowedly arranged for that end. It rarely enters into any one's head that collections are as absolutely necessary for the advancement of natural history studies, as books to the literary student, though it is allowed on all hands that natural history is of great importance in general education. Until this anomaly be removed by the re-arrangement of the museums which require it, and the establishment of new ones, it is hopeless to expect the natural sciences to flourish as they should flourish, or for them to assume the importance which they deserve in the studies of this country. To the obvious remark that the fruits of English natural science are not worse than those of our neighbours, it may be answered that what has been done is the result of personal effort overcoming obstacles, and succeeding in spite of disadvantages. The fact that some men can swim does not render life-belts unnecessary for those who cannot. 